\title{
Apoptosis and Cancer: Mutations Relationship within Caspase 2 Genes in Turk Male Patients
}

\author{
Orcun İŞLER ${ }^{1}$, Nesrin TURAÇLAR ${ }^{2}$ and Hasibe Cingilli VURAL ${ }^{1}$ \\ ${ }^{1}$ Selcuk University, Science Faculty, Department of Molecular Biology, 42079 Selçuklu, Konya, Turkey, \\ ${ }^{2}$ Vocational School of Health Services, Selcuk University, Konya, Turkey,drnesrinturaclar@yahoo.com
}

Adress for Corresponding : Dr. Hasibe Cingilli VURAL, hcvural@gmail.com

\begin{abstract}
Prostate cancer is the most frequently diagnosed male cancer in developed countries. Prostate cancer is the most common cancer diagnosed among men in Turkey, accounting for $42.5 \%$ of all cancer cases in men. It ranks second after lung cancer as the underlying cause of cancer death in Turk men. If cancer is a disease where too little apoptosis occurs there are other diseases where too much apoptosis is thought to be part of the problem. Caspases and apoptotic process very important role in modern cancer treatment. For this reason, we study and analyzed 2 exons of the human caspase 2 gene, using a strategy combining RT-PCR amplification and HRM, followed in the second study, considered to investigate the associations between prostate cancer and caspase 2 gene expression and nucleotide sequence analysis in 12 individulas with prostate cancer and healthy persons. As a result of working, variant- 1 and variant- 2 of caspase- 2 gene mutation was identified in the tissues of the prostate using HRM method. For variant-1, 4 number one mutation was detected in the samples, while for variant-2, 2 numbered examples of mutation has been identified. According to the statistical evaluation in our study, there was significant difference in CSP2 mutations. At the same time, it has been evaluated with one-to-one correspondence tests whether presence of CSP2 mutation has relationship with the development of any clinical symptoms while diagnostic criteria.
\end{abstract}

Keywords: Apoptosis, Caspase, Mutation, RT-PCR

\section{Introduction}

Prostate cancer is the most frequently diagnosed male cancer in developed countries. Despite recent advancements in the treatment and management of prostate cancer, it still remains the most common malignancy [1], and second leading cause of cancerrelated deaths among men in the Turkey. On average, one out of every four people will have cancer in their lifetime. Although inherited cancers account for only a small fraction of all tumours, most cancers are caused by a mix of hereditary and environmental factors [2].

Multicellular organisms employ two main mechanisms for the elimination of cells: necrosis and apoptosis [3]. Necrosis may be triggered by the rupture of the plasmatic membrane and may be accompanied by formation of an inflammatory process. On the contrary, apoptosis involves a "cleaner'" type of death, in which the chromatin is condensed; the DNA becomes

Manuscript received: $8^{\text {st }}$ Dec 2014

Reviewed: $16^{\text {th }}$ Dec Aug 2014

Author Corrected: $19^{\text {th }}$ Dec 2014

Accepted for Publication: $13^{\text {th }}$ Jan 2015 fragmented forming vesicles known as "apoptotic bodies". Biochemically, the main features of apoptosis include caspase cascade activation and DNA fragmentation. Upon receiving specific signals instructing the cells to undergo apoptosis a number of distinctive changes occur in the cell. A family of proteins known as caspases are typically activated in the early stages of apoptosis [4]. Apoptosis is coordinated by a family of cysteine proteases, which are activated by frequently divergent proapoptotic stimuli [5].

Activation of the caspase cascade has been correlated with the onset of apoptosis [6]. Caspases are synthesized as relatively inactive precursors that require proteolytic processing for activation [6,7]. Caspases are cysteine proteases that primarily serve two functions: the processing and activation of proinflammatory cytokines, and the cleavage of multiple proteins during apoptosis to allow the ordered dismantling of cells that are undergoing death $[8,9]$. 
Research Article

In the absence of active caspases cells do not undergo caspase independent cell death and instead could survive an insult and promote clonogenic tumor growth [10]. Thus, it has been suggested that caspases can be viewed as tumor-suppressor proteins. Caspase family of cysteinyl-proteases plays the key role in the initiation and execution of programmed cell death.

Impaired apoptosis is involved in tumor initiation and progression, since apoptosis normally eliminates cells with increased malignant potential such as those with damaged DNA or aberrant cell cycling $[11,12]$. Most prostate cancer cells have a protracted history of development, suggesting that prostate cancer cells must have evolved various mechanisms to subvert the apoptotic program [13]. Impaired apoptosis signaling and extended cell survival seem to be closely associated with prostate tumor initiation, metastasis and progression to the androgen-insensitive state [14]. Caspase-2 was reported to be involved in a number of apoptotic pathways triggered by various stimuli. The caspase-2 gene generates two main splice variants (Casp-2L and Casp-2S) that fulfill either pro- or antiapoptotic functions, respectively [15]. Binding of Casp2 pre-mRNA to RBM5 protein results in the accumulation of Casp-2L, whereas deletion or mutation of the RBM5-binding site in the Casp-2 pre-mRNA leads to accumulation of the Casp-2S isoform. Another mechanism that might lead to accumulation of Casp-2S is its transcriptional regulation by TAp73 and $\mathrm{DNp} 73$ [16]. It is possible that survival promoted by the caspase-2 splice variant might be responsible for regulation of its tumor-suppressor function. Furthermore, novel roles of caspase- 2 in non-apoptotic processes, such as cell cycle regulation and DNA repair have been suggested [17]. Caspase- 2 may have more distinctive properties, and understanding the function of caspase- 2 is challenging. The function of capase- 2 is still poorly understood. While containing the long prodomain and being able to respond to a variety of apoptotic stimuli, and plays an important role for DNA damage induced apoptosis [18]. Caspsase-2 is not really essential for most physiological cell deaths. Caspase-2, the most conserved member of the caspase family, has long been recognized as an important protein in the regulation of apoptosis. In addition, a tumor-suppressor function has been suggested for caspase-2. While not expressed in individuals suffering from cancer in healthy individuals show caspase expression. In addition, a tumor-suppressor function has been suggested for caspase-2. Furthermore, caspase-2 was recently implicated in cell cycle regulation. Because many of the tumor-suppressor proteins are known to play a role in cell cycle regulation, it is likely that these two newly assigned functions for caspase-2 are interrelated. In order to control the role of caspases in apoptotic and non-apoptotic processes, these enzymes might have acquired distinct activation mechanisms. Indeed, the specific activation of caspase-2 in different complexes, located in various intracellular compartments, might explain its distinct functions. Despite the early discovery of caspase-2, its physiological function has long remained an enigma. A number of recent publications now suggest not just one, but multiple functions, including roles in apoptosis, DNA repair and tumor suppression. How can one enzyme have so many talents? Considering the diversity of interaction partners and the specific mode of proapoptotic action proposed in these studies, caspase-2 might in fact represent a primordial protease serving numerous pathways, established before the advent of a more elaborate functionally diversified caspases system.

This article discusses various observations that relate to caspase-2 functions in apoptosis, the DNA damage response and tumour suppression, and attempts to reconcile reports that have often been contradictory and controversial. It has been evaluated with one-to-one correspondence tests whether presence of CSP2 mutation has relationship with the development of any clinical symptoms while diagnostic criteria. According to the statistical evaluation in our study, there was significant difference in CSP2 mutations. At the same time, it has been evaluated with one-to-one correspondence tests whether presence of CSP2 mutation has relationship with the development of any clinical symptoms while diagnostic criteria.

\section{Material and Methods}

\section{Tumor Samples}

Paraffine blocks of prostate pathologies were derived from the archives of the Department of Pathology in Faculty of Medicine at the University of Konya Necmettin Erbakan, Turkey. Namely, Paraffineembedded prostate cancer tissue specimens of 12 prostate cancer patients were used in this study. Age range was 50-74 years were males. These patients went to physicians to be demonstrate a variety of serious symptoms of prostate cancer, e.g, difficulty in voiding, urodynia, urgent and frequent urination, and hematuria. Their prostates were examined by one or more of the following means: rectal ultrasound detection, digital rectal examination, computed tomography, and magnetic resonance imaging. Biopsy was performed for the patients who were suspected to have prostate cancer, 
Research Article

and all specimens were from archived paraffine blocks that were collected specifically for this study. Control

samples were obtained from natural or healthy tissue.

\section{Molecular Material}

Variant-1 and variant-2 belonging to caspase-2 of primers were obtained from the Teknik Kimya, from Turkey (Table 1).

Table 1: Variant-1 and variant-2 belonging to caspase-2 of primers

\begin{tabular}{|l|l|}
\hline Caspase-2 Variant-1 & $\begin{array}{l}\text { F: 5'-CAC CTC CCC ATC ATC CAC-3' } \\
\text { R: 5'-GAG ATT CCC ACA TCC CTG AG-3' }\end{array}$ \\
\hline Caspase-2 Variant- 2 & $\begin{array}{l}\text { F: 5'- GCA CTT ATC AAG GAT CGG GA-3' } \\
\text { R: 5'- ATG GGC ACA GGA AAC AAG TC-3' }\end{array}$ \\
\hline
\end{tabular}

\section{Deparaffinization of Samples}

Deparaffinization removes the bulk of paraffin from the paraffin-embedded sample. A number of techniques for deparaffinization are known and any suitable technique can be used with the present invention. In this study, we used a method of the invention utilizes washing with an organic solvent to dissolve the paraffin. Xylene was used to remove paraffin effectively from the tissue sample without adversely affecting DNA isolation. Xylene is the preferred solvent for use in the methods of the invention. Paraffin was typically removed by washing with xylene vigorous mixing followed by centrifugation. Samples are centrifuged at a speed sufficient to cause the tissue to pellet in the tube, about $20,000 \times \mathrm{g}$. After centrifugation, the organic xylene supernatant is discarded. And then, tissue samples were passed a series of alcohol (Absolute alcohol and 75\% ethyl alcohol) and were centrifuged in each of steps. Thus, the paraffin was removed from tissue samples [19].

\section{Patient Anamnesis}

The study was approved by the local ethics committee, all patients gave written informed consent for participation in the study. Patients with either prostate cancer and other primary cancer, and family history of cancer in terms of patient age and gleason score (see Table 2) and healthy individuals without prostate cancer were included in the study. In addition to working in an individual's age and eligibility criteria in terms of gleason scores already published in previous studies. Tissue samples taken from patients according to pathological findings were recruited between 2010 and 2011.

Table 2: Prostate Parameters

\begin{tabular}{|l|l|l|l|l|l|}
\hline \multicolumn{2}{|c|}{ Prostate Cancer Characteristics } \\
\hline Case No & $\begin{array}{c}\text { Patient } \\
\text { Age }\end{array}$ & $\begin{array}{c}\text { Gleason Score } \\
\text { (ng/dl) (PSA) }\end{array}$ & $\begin{array}{c}\text { TNM (Tumor- } \\
\text { lymph nodes- } \\
\text { metastasis) }\end{array}$ & $\begin{array}{c}\text { Family history of } \\
\text { cancer and other } \\
\text { cancers }\end{array}$ & $\begin{array}{c}\text { Personal history of } \\
\text { cancer and the other } \\
\text { cancers }\end{array}$ \\
\hline 2 & 58 & 5 & NA & No & No \\
\hline 13 & 49 & 5 & NA & No & No \\
\hline 19 & 69 & 6 & $\mathrm{~T}_{1 \mathrm{a}}$ & testes & No \\
\hline 20 & 59 & 5 & $\mathrm{~T}_{1 \mathrm{a}}$ & No & No \\
\hline 23 & 70 & 8 & $\mathrm{~T}_{2 \mathrm{~b}}$ & No & No \\
\hline 28 & 89 & 5 & $\mathrm{NA}_{\mathrm{A}}$ & No & No \\
\hline 30 & 62 & 8 & $\mathrm{~T} 1 \mathrm{c}$ & Bladder & No \\
\hline 31 & 51 & 5 & $\mathrm{~T}_{2 \mathrm{a}}$ & No & No \\
\hline 35 & 58 & 7 & $\mathrm{~T}_{1 \mathrm{c}}$ & Bladder & Colon \\
\hline 36 & 65 & 7 & $\mathrm{~T}_{2 \mathrm{a}}$ & Testis, colon & Lung \\
\hline 42 & 72 & 9 & $\mathrm{~N}_{0}$ & Kidney & No \\
\hline 48 & 67 & 7 & $\mathrm{~T}_{1 \mathrm{c}}$ & Bladder & \\
\hline
\end{tabular}


NA; normal and close to normal, healthy (According to the data of total)

$\mathrm{N}_{0}$; tumor cells absent from regional

$\mathrm{T}_{1 \mathrm{a}}$; benign prostate tumor ( $5 \%$ cancer, $95 \%$ good-naturated of prostate tissue)

$\mathrm{T}_{1 \mathrm{c}}$; the tumor have been identified at this stage

$\mathrm{T}_{2 \mathrm{a}}$; tumor localized one side of prostate tissue

$\mathrm{T}_{2 \mathrm{~b}}$; the cancer has started to metastasize (between individuals is observed under the age of 71

No; not observed in other types of cancer (individual and familial)

\section{DNA Isolation Procedure}

Formalin-fixed paraffin samples were cut into $10-\mu \mathrm{m}$ sections. The sections were pulverized under liquid nitrogen condition using microdismembrator (B. Braun, Melsungen, Germany) of each sample, $0.1 \mathrm{~g}$ of pulverized tissue powder was resuspended in $1 \mathrm{ml}$ of xylene and left for 15 minutes at $55^{\circ} \mathrm{C}$. The suspension was then centrifuged at $14000 \mathrm{~g}$ for 5 minutes. The pellet was suspended in $0.1 \mathrm{ml}$ of xylene and processed as above for the second time. The resulted sediment was mixed with $100 \%$ ethanol and processed with xylene lysis buffer [Tris, sodium dodecyl sulfate, ethylenediamine tetraacetic acid (EDTA)]. A lysis buffer containing $300 \mu \mathrm{g} / \mathrm{ml}$ of proteinase $\mathrm{K}$ was added to the pellet, mixed and incubated at $55^{\circ} \mathrm{C}$ for an overnight period. The DNA was extracted following the use of phenol-chloroform procedure, then dissolved in TE buffer (Tris-HCl and EDTA) and stored at $4^{\circ} \mathrm{C}$. Furthermore, Genomic DNA was isolated from paraffin-embedded prostate cancer tissue and the normal tissue using the tissue kit (Roche) [20].

\section{HRM}

Mutation scanning techniques are used to detect sequence variants without the need for prior knowledge of the identity or precise location of the variant, in contrast with genotyping techniques, which determine the status of a specific variant. High-resolution melting is a recently developed method that shows great potential as a mutation scanning technique [21].

\section{Results}

The apoptosis process is mediated by sequential activation of caspases. To understand apoptotic cell death, therefore, many studies have examined the caspase activation mechanism. Despite intense structural and biochemical investigations, there are still many unknown features of the caspase and caspase activation mechanism. This article summarizes the most recent structural studies on the caspase-activating complexes. As a result of working, variant-1 and variant-2 of caspase-2 gene mutation was identified in the tissues of the prostate using HRM method. For variant-1, 4 number one mutation was detected in the samples, while for variant-2, 2 numbered examples of mutation has been identified.

These data show that loss of caspase- 2 results in an increased ability of cells to acquire a transformed phenotype and become malignant. This suggests that the role of caspase- 2 in cell death is redundant or is compensated by other caspases. However, there is indirect evidence to suggest that caspase- 2 may play some role in cancer. Our data provide strong support for a context-dependent function of caspase-2 in apoptosis.

This study investigates the role of caspase- 2 in apoptotic signaling of human male prostate cells. In addition, we were also evaluated samples from individuals with prostate cancer the most conserved member of the caspase family and caspase-2, known to act as a tumor suppressor with HRM the method of analysis aimed to identify single point mutations.

As a result of working, variant-1 and variant-2 of caspase-2 gene mutation was identified in the tissues of the prostate using HRM method. For variant-1, 4 number one mutation was detected in the samples, while for variant-2, 2 numbered examples of mutation has been identified (Figure 1 and Figure 2).

This article reviews the current knowledge on mutations of apoptosis genes involved in the pathogenesis of human diseases and summarizes the gradual transformation of discoveries in apoptosis research into benefits for the clinical management of diseases.

We can summarize that significant caspase-2 activation is associated with apoptosis induction tested in samples of patients with prostate cancer cells an least partially, for the induction as well. 
Figure 1: Variant-1 to caspase-2 image analysis of the HRM (WT: wild type)

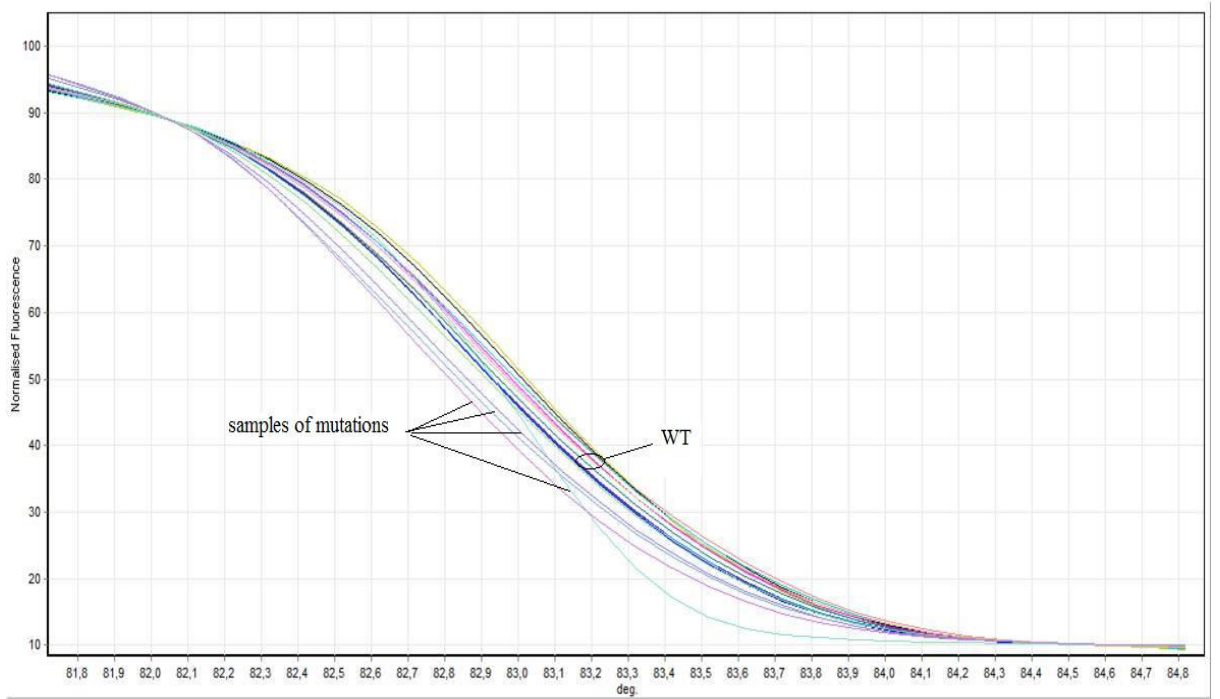

Figure 2: Variant-1 to caspase-2 image analysis of the Melting curve (WT: wild type)

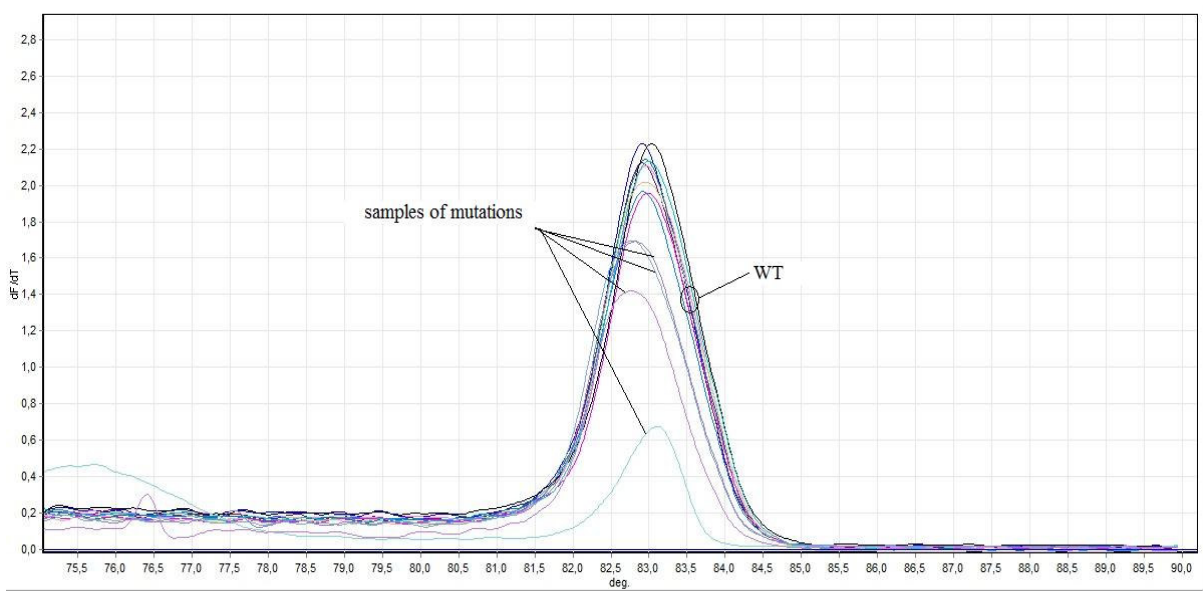

Figure 3: Variant-2 to caspase-2 image analysis of the HRM (WT: wild type)

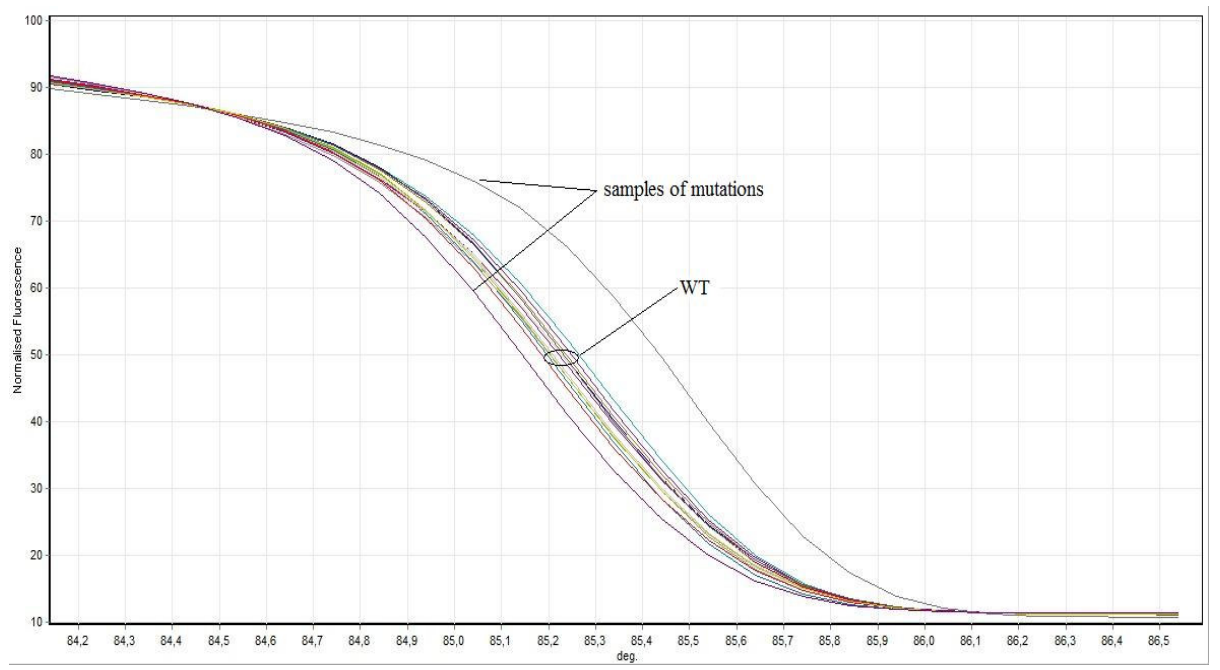


Research Article

Figure 4: Variant-2 to caspase-2 image analysis of the Melting curve (WT: wild type)

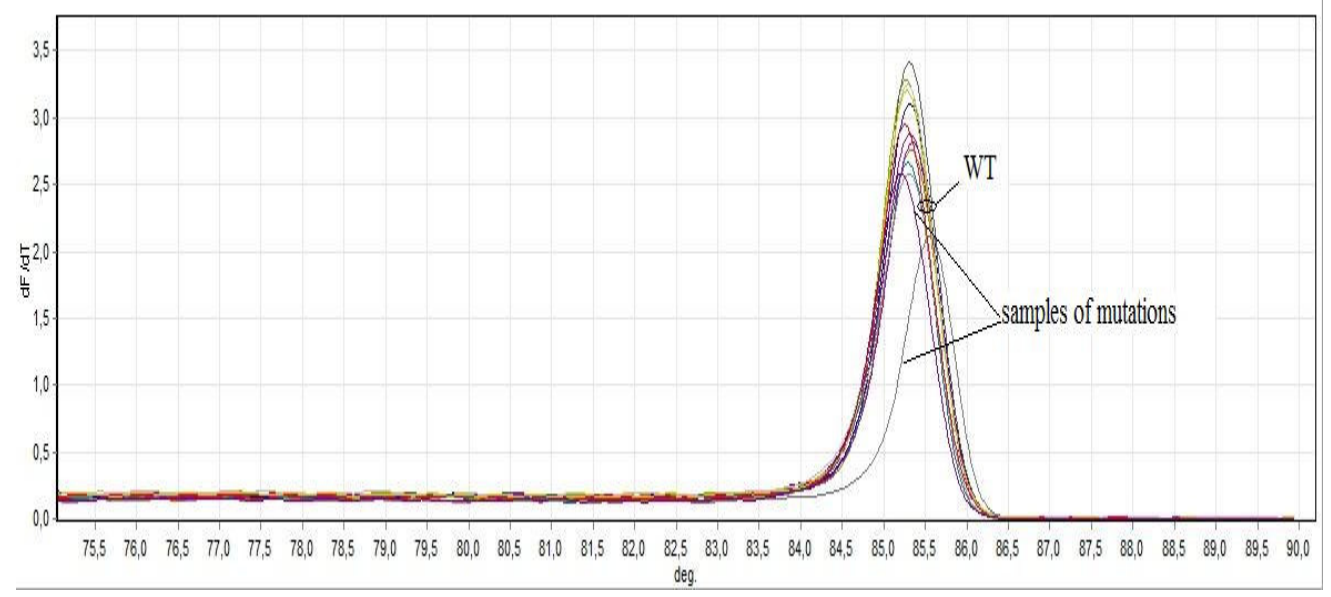

\section{Discussion}

The caspases have been divided into two groups: initiators and effectors. First group of initiator or apical caspases (caspases-2, -8, -9, -10, and, probably, -11) activate the second-group of caspases (caspases-3, -6, and -7). The effector or downstream caspases are able to directly degrade multiple substrates including the structural and regulatory proteins in the cell nucleus, cytoplasm, and cytoskeleton [22]. Proteolysis of cellular substrates by caspases (cysteine-dependent aspartatespecific proteases) is one of the hallmarks of apoptotic cell death [23]. Although the activation of apoptotic caspases is considered a 'late-stage' event in apoptosis signaling, past the commitment stage, one caspase family member, caspase-2, splits the cell death community into half - those searching for evidence of an apical initiator function of this molecule and those considering it as an amplifier of the apoptotic caspase cascade, at best, if relevant for apoptosis at all. This review screens past and present biochemical as well as genetic evidence for caspase-2 function in cell death signaling and beyond [24]. Caspase-2 is the second identified caspase. It contains a CARD domain and recruit multi-protein complex "PIDDosome2 through CARD binding with RAIDD (RIP associated ICH-1/ ECD3 homologous protein with a death domain) [25].

The adaptor proteins RAIDD and PIDD (p53 induced protein with death domain) in this complex are essential components for the activation for caspase-2 [26]. Caspase-2 appears to act upstream of mitochondrial permeabilisation by cleaving and activating Bid, and plays an important role for DNA damage induced apoptosis [27]. A recent study demonstrated that disruption of caspase-2 has a significant impact on mouse aging, suggesting that caspase- 2 deficiency compromised the animal's ability to clear oxidative damaged cells [28]. Caspase-2 may have more distinctive properties, and understanding the function of caspase- 2 is challenging. Given that comparatively few substrates have been found for caspase-2, as well as its unique characteristics, the exact apoptotic and nonapoptotic function of caspase- 2 has been the subject of much debate.

As described above, a number of anticancer therapies are being tested that influence the expression and/or activity of factors that regulate apoptosis.

Targeting caspases and apoptotic machinery will play an increasingly important role in future modern cancer therapy, and approaches are being developed that allow "'on demand"'activation of expression.

Caspase family proteases are key factors in apoptosis, and the related research can help us to obtain the essence of the above phenomena at the molecular level and enable us to make breakthroughs in the therapy of tumors, immune system diseases and nervous system diseases using the artificial control of apoptosis [29].

\section{Acknowledgment}

This study was partially supported by Selcuk University Archeometry Laboratory and Scientific Research Foundation of Selcuk University (BAP) for providing foundation (Project number: 09401106).

Funding: Nil,

Permission from IRB: Yes

Conflicts of interest: The authors report no conflicts of interest 


\section{References}

1. Rosenthal SA, Sandler HM. Treatment strategies for high-risk locally advanced prostate cancer. Nat Rev Urol. 2010 Jan;7(1):31-8. doi: 10.1038/nrurol.2009.237.

2. $\mathrm{Xu} \mathrm{J}$. and the International Consortium for the Prostate Cancer Genetics. Combined analysis of hereditary prostate cancer linkage to 1q24-25: results from the 772 hereditary prostate cancer families from the International Consortium for Prostate Cancer Genetics. Am J Hum Genet. 2000 Mar;66(3):945-57.

3. Bowen C, Voeller HJ, Kikly K, Gelmann EP.. Synthesis of procaspases-3 and -7 during apoptosis in prostate cancer cells. Cell Death Differ. 1999 May;6(5):394-401.

4. Bruckheimer EM, Kyprianou N. Apoptosis in prostate carcinogenesis. A growth regulator and a therapeutic target. Cell Tissue Res. 2000 Jul;301(1):153-62.

5. Coffey RN, Watson RW, Fitzpatrick JM. Signaling for the caspases: their role in prostate cell apoptosis $J$ Urol. 2001 Jan;165(1):5-14.

6. Coté J, Dupuis S, Jiang Z, Wu JY. Caspase-2 premRNA alternative splicing: Identification of an intronic element containing a decoy 3' acceptor site. Proc Natl Acad Sci U S A. 2001 Jan 30;98(3):938-43. Epub 2001 Jan 23.

7. Fischer U, Janssen K, Schulze-Osthoff K. Does caspase inhibition promote clonogenic tumor growth? Cell Cycle.2007 Dec 15;6(24):3048-53.Epub 2007 Oct 2

8. Fisher DE. Apoptosis in cancer therapy: crossing the threshold. Cell. 1994 Aug 26;78(4):539-42.

9. Salvesen GS. Caspases and apoptosis. Essays Biochem. 2002;38:9-19.

10. Hombach-Klonisch S, Paranjothy $\mathrm{T}$, Wiechec E, Pocar P, Mustafa T, Seifert A, Zahl C, Gerlach KL, Biermann K, Steger K, Hoang-Vu C, SchulzeOsthoff K, Los M. Cancer stem cells as targets for cancer therapy: selected cancers as examples. Arch Immunol Ther Exp (Warsz). 2008 May-Jun;56(3):16580.doi: 10.1007/s00005-008-0023-4. Epub 2008 May 30

11. Jiang G, Yang F, Li M, Weissbecker K, Price S, Kim KC, La Russa VF, Safah H, Ehrlich M. Imatinib (ST1571) provides only limited selectivity for CML cells and treatment might be complicated by silent BCRABL genes. Cancer Biol Ther. 2003 Jan-Feb;2(1):103-8.
12 Jin S, DiPaola RS, Mathew R, White E. Metabolic catastrophe as a means to cancer cell death. J Cell Sci. 2007 Feb 1;120(Pt 3):379-83.

13. Klonisch T, Wiechec E, Hombach-Klonisch S, Ande SR, Wesselborg S, Schulze-Osthoff K, Los M. Cancer stem cell markers in common cancers - therapeutic implications. Trends Mol Med. 2008 Oct;14(10):450-60. doi: 10.1016/j.molmed.2008.08.003. Epub 2008 Sep 3.

Kops GJ, Weaver BA, Cleveland DW. On the road to cancer: aneuploidy and the mitotic checkpoint. Nat Rev Cancer. 2005 Oct;5(10):773-85.

15. Read SH, Baliga BC, Ekert PG, Vaux DL, Kumar S. A novel Apaf-1-independent putative caspase-2 activation complex. J Cell Biol. 2002 Dec 9;159(5):73945. Epub 2002 Dec 2.

16. Toh WH, Logette E, Corcos L, Sabapathy K. TAp73beta and DNp73beta activate the expression of the pro-survival caspase-2S. Nucleic Acids Res. 2008 Aug;36(13):4498-509. doi: 10.1093/nar/gkn414. Epub 2008 Jul 8.

17. Shi Y. Mechanisms of caspase activation and inhibition during apoptosis. Mol Cell. 2002 Mar;9(3):459-70.

18. Robertson JD, Gogvadze V, Kropotov A, Vakifahmetoglu H, Zhivotovsky B, Orrenius S. Processed caspase- 2 can induce mitochondria-mediated apoptosis independently of its enzymatic activity. EMBO Rep. 2004 Jun;5(6):643-8. Epub 2004 May 21.

19. Wu L, Patten N, Yamashiro CT, Chui B. Extraction and amplification of DNA from formalin-fixed, paraffin-embedded tissues. Appl Immunohistochem Mol Morphol. 2002 Sep;10(3):269-74.

20. Faulkner SW, Leigh DA. Universal amplification of DNA isolated from small regions of paraffin-embedded, formalin-fixed tissue. Biotechniques. 1998 Jan;24(1):4750 .

21. Wittwer CT, Reed GH, Gundry CN, Vandersteen JG, Pryor RJ. High-resolution genotyping by amplicon melting analysis using LCGreen. Clin Chem. 2003 Jun;49(6 Pt 1):853-60.

22. Wang, Z. B., Liu, Y. Q., Cui, Y. F., Pathways to caspase activation. Cell Biol Int. 2005 Jul;29(7):489-96.

Available online at: www.ijmrr.in 33 | P a g e 
23. Ho LH, Read SH, Dorstyn L, Lambrusco L, Kumar $\mathrm{S}$. Caspase-2 is required for cell death induced by cytoskeletal disruption. Oncogene. 2008 May 29;27(24):3393-404. doi: 10.1038/sj.onc.1211005. Epub 2008 Jan 14.

24. Zhang Y, Padalecki SS, Chaudhuri AR, De Waal E, Goins BA, Grubbs B, Ikeno Y, Richardson A, Mundy GR, Herman B. Mech Ageing Dev. 2007 Feb;128(2):213-21. Epub 2006 Dec 22.

25. Tinel A, Tschopp J. The PIDDosome, a protein complex implicated in activation of caspase- 2 in response to genotoxic stress. Science. 2004 May 7;304(5672):843-6. Epub 2004 Apr 8.

26. Fushimi K, Ray P, Kar A, Wang L, Sutherland LC, Wu JY. Up-regulation of the proapoptotic caspase 2 splicing isoform by a candidate tumor suppressor,
RBM5. Proc Natl Acad Sci U S A. 2008 Oct 14;105(41):15708-13. doi: 10.1073/pnas.0805569105. Epub 2008 Oct 7.

27. Guo Y, Srinivasula SM, Druilhe A, FernandesAlnemri T, Alnemri ES. Caspase-2 induces apoptosis by releasing proapoptotic proteins from mitochondria. J Biol Chem. 2002 Apr 19;277(16):13430-7. Epub 2002 Feb 6.

28. Stennicke HR, Salvesen GS. Catalytic properties of the caspases. Cell Death Differ. 1999 Nov;6(11):1054-9.

29. Bonzon C, Bouchier-Hayes L, Pagliari LJ, Green DR, Newmeyer DD. Caspase-2- induced apoptosis requires bid cleavage: a physiological role for bid in heat shock induced death. Mol Biol Cell. 2006 May;17(5):2150-7. Epub 2006 Feb 22.

\section{How to cite this article?}

Orcun İŞLER, Nesrin TURAÇLAR, Hasibe Cingilli VURAL. Apoptosis and Cancer: Mutations Relationship within Caspase 2 Genes in Turk Male Patients. Int J Med Res Rev 2015;3(1):27-34. doi:10.17511/ijmrr.2015.i1.06 